\title{
Bioproduction of citric acid exposed to lithium dodecyl sulfate
}

\author{
Umesh Prasad Chaurasia* \\ Department of Chemistry, T. R. M. Campus, T.U., Birganj, Nepal Email: \\ uchaurasia1000@gmail.com
}

\begin{abstract}
The efficacy of lithium dodecyl sulfate on bioproduction of citric acid by some fungal strains such as Aspergillus carbonarius NCIM -2097, Aspergillus saitoi NCIM -2056, Aspergillus usumii NCIM - 2045, Aspergillus wentii NCIM - 2020 and Aspergillus-niger NCIM -2101 has been assessed. It has been found that the fungal strain Aspergillus-niger NCIM -2101 has been found most suitable to give higher yield of citric acid. The micelle; i.e. lithium dodecyl sulfate under trial has stimulatory effect on bioproduction of citric acid and enhances the yield of citric acid to an extent of $12.794 \%$ higher in comparison to control fermenter flasks, i.e., $8.566 \mathrm{~g} / 100 \mathrm{ml}$ in 12 days of optimum incubation period, $1.8 \mathrm{pH}$ and $30{ }^{\circ} \mathrm{C}$ temperature with $28 \%(w / v)$ molasses solution alongwith other nutritional ingredients.
\end{abstract}

Key words: Molasses, citric acid fermentation, lithium dodecyl sulfate and Aspergillus niger NCIM2101

\section{Introduction}

A micelle is formed when a variety of molecules including soaps and detergents are added to water. The molecule may be a fatty acid, a salt of a fatty acid (soap), phospholipids, or other similar molecules ${ }^{1-}$ ${ }^{10}$. The molecule must have a strongly polar "head" and a non-polar hydrocarbon chain "tail". The polar head of the molecule presents itself for interaction with the water molecules on the outside of the micelle. Micelles either accelerates or retards the organic reactions depending on its nature ${ }^{11-20}$. It is assumed that micelles are moderators of enzyme actions in some biological systems ${ }^{21-23}$. There are several known micelles, but a very few micelles have been used in submerged fermentation processes ${ }^{24-42}$. Since micellar effect on fermentation studies especially citric acid fermentation is relatively new and almost unexplored, it needs careful and specific experimentations. In the present investigation the author has made an attempt to study the effect of lithium dodecyl sulfate on citric acid fermentation by Aspergillus niger NCIM-983

\section{Experimental}

The influence of lithium dodecyl sulfate on bioproduction of citric acid by Aspergillus niger NCIM2101. The composition of the production medium for production of citric acid by Aspergillus niger NCIM-2101 has been prepared as follows :

Molasses: $28 \%(\mathrm{w} / \mathrm{v}), \mathrm{NH}_{4} \mathrm{NO}_{3}: 0.25 \%, \mathrm{KH}_{2} \mathrm{PO}_{4}: 0.25 \%, \mathrm{MgSO}_{4} \cdot 7 \mathrm{H}_{2} \mathrm{O}: 0.25 \%, \mathrm{pH}: 1.8$

The $\mathrm{pH}$ of the production medium was adjusted to 1.8 by adding requisite amount of $\mathrm{KClHCl}$ buffer solution, and this $\mathrm{pH}$ was also ascertained by a $\mathrm{pH}$ meter. The above composition medium represents

${ }^{*}$ Corresponding author 


\section{J. Nepal Chem. Soc., Vol.37, 2017}

volume of a fermenter flask, i.e., "100ml" production medium for bioproduction of citric acid by Aspergillus niger NCIM-2101. Now, the same production medium for bioproduction of citric acid by Aspergillus niger NCIM-2101 was prepared for 99-fermenter flask, i. e; each contained '100ml' of production medium.

The above 99-fermenter flasks were then arranged to 11-sets each comprising of 9-fermenter flasks. Each set was then rearranged in 3-subsets, each consisting of 3-fermenter flasks. The remaining 9fermenter flasks out of 99-fermenter flasks were kept as control and these were also rearranged in 3subsets each consisting of 3 fermenter flasks.

After preparing the above sets of fermenter flasks M/1000 solution of lithium dodecyl sulfate was prepared and from the above lithium dodecyl sulfate solution 1.0, 2.0, 3.0, 4.0, 5.0, 6.0, 7.0, 8.0, 9.0 and $10 \mathrm{ml}$ was added to the fermentation flasks of above 1st to 10th sets respectively. The control fermenter flasks contained no lithium dodecyl sulfate.

Now, the total volume in each fermenter flasks was made up to $100 \mathrm{~mL}$ by adding requisite amount of distilled water. Thus, the molar concentration of lithium dodecyl sulfate in 1st, 2nd, 3rd, 4th, 5th, 6th, 7th, 8th, 9th and 10th subsets were approximately as given below :

\begin{tabular}{|c|c|}
\hline A x $10^{-\mathrm{x}} \mathrm{M}$, i.e., & \\
\hline $1.0 \times 10^{-5} \mathrm{M}$ & $6.0 \times 10^{-5} \mathrm{M}$ \\
\hline $2.0 \times 10^{-5} \mathrm{M}$ & $7.0 \times 10^{-5} \mathrm{M}$ \\
\hline $3.0 \times 10^{-5} \mathrm{M}$ & $8.0 \times 10^{-5} \mathrm{M}$ \\
\hline $4.0 \times 10^{-5} \mathrm{M}$ & $9.0 \times 10^{-5} \mathrm{M}$ \\
\hline $5.0 \times 10^{-5} \mathrm{M}$ & $10.0 \times 10^{-5} \mathrm{M}$ \\
\hline
\end{tabular}

$\mathrm{A}=$ amount of lithium dodecyl sulfate, in $\mathrm{mL}$, i.e., $1.0 \mathrm{~mL} \ldots .$. to $10 \mathrm{~mL}$.

$\mathrm{x}=$ Molarity of the lithium dodecyl sulfate solution

The above fermenter flasks were then sterilized, cooled inoculated and incubated at $32^{\circ} \mathrm{C}$ and analysed after 8,12 and 14 days for citric acid formed ${ }^{43}$.

\section{Results and Discussion}

\section{The influence of lithium dodecyl sulfate}

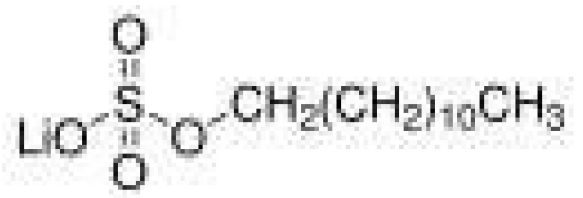

The data given in the table 1 shows that the micelle lithium dodecyl sulfate has also been found stimulatory for the citric acid production by Aspergillus niger NCIM-2101. From the data given in the table-3 it is obvious that lithium dodecyl sulfate influences the citric acid fermentation process in different phases. The main characteristics of the lithium dodecyl sulfate is as follows: 
(i) Lithium dodecyl sulfate is stimulatory at its all molar concentrations used during the course of fermentation for citric acid bioproduction by Aspergillus niger NCIM-2101, i. e., from $1.0 \times 10^{-5} \mathrm{M}$ to $10.0 \times 10^{-5} \mathrm{M}$.

(ii) The molar concentration $1.0 \times 10^{-5} \mathrm{M}, 2.0 \times 10^{-5} \mathrm{M}, 3.0 \times 10^{-5} \mathrm{M} 4.0 \times 10^{-5} \mathrm{M}, 5.0 \times 10^{5} \mathrm{M}$ and $6.0 \times$ $10^{-5} \mathrm{M}$ of lithium dodecyl sulfate influence the yield of citric acid in a approximately regular increasing order after each state, i. e., $0.618 \%, 1.891 \%, 3.490 \%, 6.397 \%, 8.489 \%$ and $12.794 \%$

(iii) The molor concentration at $7.0 \times 10^{-5} \mathrm{M}$ to $10.0 \times 10^{-5} \mathrm{M}$ of lithium dodecyl sulfate also influences the productivity of citric acid in a regular decreasing manner. The $\%$ increase in the yield of citric acid at respective molar concentration of lithium dodecyl sulfate has been found to be as follows : $10.494 \%, 8.592 \%, 4.296 \%$ and $2.393 \%$

(iv) The maximum yield of citric acid, i.e; $9.662 \mathrm{~g} / 100 \mathrm{ml}$ in the presence of lithium dodecyl sulfate was observed at $6.0 \times 10^{-5} \mathrm{M}$ molar concentration in 12 days of optimum incubation period which is $12.794 \%$ higher in comparison to control fermenter flasks, i.e; $8.566 \mathrm{~g} / 100$ $\mathrm{ml}$ in the same times course and other same experimental parameters.

(v). The higher molar concentrations of lithium dodecyl sulfate were not much favourable for citric acid production by Aspergillus niger NCIM-2101 So the gradual addition of the micelle lithium dodecyl sulfate after molar concentrations

$6.0 \times 10^{-5} \mathrm{M}$ and onwards were not beneficial for the citric acid fermentation process.

Table 1: Bioproduction of citric acid exposed to Lithium dodecyl sulfate

\begin{tabular}{|l|c|c|c|c|}
\hline $\begin{array}{c}\text { Concentration } \\
\text { of micelle used } \\
\mathrm{A} \times 10^{-\mathrm{x}} \mathrm{M}\end{array}$ & $\begin{array}{c}\text { Incubation } \\
\text { period in } \\
\text { days }\end{array}$ & $\begin{array}{c}\text { Molasses* } \\
\text { left unfermented } \\
\text { in g/100 ml }\end{array}$ & $\begin{array}{c}\text { Yields of citric } \\
\text { acid* in } \\
\mathrm{g} / 100 \mathrm{ml}\end{array}$ & $\begin{array}{c}\text { \% of Citric acid } \\
\text { increased after } \\
12 \text { days }\end{array}$ \\
\hline Control & 8 & 6.253 & 5.749 & - \\
\hline$(-)$ Micelle & 12 & 8.566 & 3.438 & - \\
\hline & 14 & 7.286 & 3.336 & - \\
\hline $1.0 \times 10^{-5} \mathrm{M}$ & 8 & 6.290 & 5.710 & +0.618 \\
\hline$(+)$ Micelle & 12 & 8.619 & 3.385 & - \\
\hline & 14 & 7.518 & 3.294 & - \\
\hline $2.0 \times 10^{-5} \mathrm{M}$ & 8 & 6.359 & 5.642 & +1.891 \\
\hline$(+)$ Micelle & 12 & 8.728 & 3.279 & - \\
\hline & 14 & 7.625 & 3.188 & - \\
\hline $3.0 \times 10^{-5} \mathrm{M}$ & 8 & 6.459 & 5.549 & +3.490 \\
\hline$(+)$ Micelle & 12 & 8.865 & 3.138 & - \\
\hline & 14 & 7.763 & 3.049 & - \\
\hline $4.0 \times 10^{-5} \mathrm{M}$ & 8 & 6.640 & 5.369 & + \\
\hline$(+)$ Micelle & 12 & 9.114 & 2.888 & 6.397 \\
\hline & 14 & 8.019 & 2.797 & - \\
\hline
\end{tabular}


J. Nepal Chem. Soc., Vol.37, 2017

\begin{tabular}{|l|l|l|l|l|}
\hline $5.0 \times 10^{-5} \mathrm{M}$ & 8 & 6.771 & 5.232 & - \\
\hline$(+)$ Micelle & 12 & 9.294 & 2.711 & +8.498 \\
\hline & 14 & 8.189 & 2.622 & - \\
\hline $6.0 \times 10^{-5} \mathrm{M}^{* *}$ & 8 & 7.040 & 4.966 & - \\
\hline$(+)$ Micelle & 12 & $9.662^{* * *}$ & 2.339 & +12.794 \\
\hline & 14 & 8.559 & 2.145 & - \\
\hline $7.0 \times 10^{-5} \mathrm{M}$ & 8 & 6.897 & 5.110 & - \\
\hline$(+)$ Micelle & 12 & 9.465 & 2.539 & +10.494 \\
\hline & 14 & 8.361 & 2.448 & - \\
\hline $8.0 \times 10^{-5} \mathrm{M}$ & 8 & 6.778 & 5.229 & - \\
\hline$(+)$ Micelle & 12 & 9.302 & 2.698 & +8.592 \\
\hline & 14 & 8.200 & 2.597 & - \\
\hline $9.0 \times 10^{-5} \mathrm{M}$ & 8 & 6.509 & 5.498 & - \\
\hline$(+)$ Micelle & 12 & 8.934 & 3.166 & +4.296 \\
\hline & 14 & 7.830 & 3.053 & - \\
\hline $10.0 \times 10^{-5} \mathrm{M}$ & 8 & 6.390 & 5.615 & - \\
\hline$(+)$ Micelle & 12 & 8.771 & 3.229 & +2.393 \\
\hline & 14 & 7.670 & 3.138 & - \\
\hline
\end{tabular}

* $\quad$ Each value represents mean of three trials

** Optimum concentration of micelle used

*** Optimum yield of citric acid

$(+)$ values indicate \% increase in the yield of citric acid after 12 days. Experimental deviation $( \pm)$ 1.5$3 \%$

\section{References}

1. A Goldsipe and D. Blankschtein, Langumir, 2005, 22, 9850.

2. G. Basu Ray, I.Chakraborty S. Ghosh and S.P. Moulik Colloid Polym, Sci., 2007, 285, 457. F.M. Kuni, A.K. Shchekin I. Rusanova and A.P. Grinin, Colloid J., 2004, 66, 174.

4. B.C. Stephenson, A. Goldsipe, K.J. Beers and D. Blankschtein J. Phys. Chem. (B) 2007, 111, 1025.

5. N. Yoshii, K. Iwahashi and S. Okazaki J. Chem. Phys. 2006, 124, 184901.

6. L. Mailbaum. A.R. Dinner and D. Chandler, J. Phys. Chem. (B), 2004, 108, 6778.

7. T. Chakraborty, S. Ghosh and S.P. Moulik J. Phys. Chem. (B), 2005, 109, 14813.

8. D. P. Tieleman, D. Van der Spoel, H. J. C. Berendsen J. Phys. Chem. 2000, 104 : 6380.

9. J.F. Hochepied and A.P.A. de Oliveira, Porgr. Colloid Polym.Sci.. 2004, 125, 68.

10. K. Shivaji Sharma and A.K. Rakshit J. Surf. Deterg., 2004, 7, 305.

11. J. Y. Lion, T. M. Huang and G. G. Chang, J. Chem. Soc. Perkin Trans., 1999, 2, 2171. 
12. H. J. Lee and G. G. Chang, J. Colloid Interface, Sci. 1998, 201, 26.

13. A. Mallick, B. Haldar and N. Chattopadhyay, J. Phys. Chem. (B), 2005, 109, 14683.

14. A. Mallick, B. Haldar, S. Maiti and N. Chattopadhyay, J. Colloid Interface, Sci. 2004, 278, 215.

15. S. K. Ghosh, P. K. Khatua, J. K. Ghosh and S. C. Bhattacharya, Spectrochimica Acta, Part A, 2005, 61, 395.

16. S. K. Saha, G. Krishnamoorty and S. K. Dogra, J. Photochem. Photobiol. A : Chem., 1999, 121, 191.

17. G. Krishnamoorty and S. K. Dogra, Chem. Phys. Lett., 2000, 323, 234.

18. M.A. El-Kemary, R. A. Khedr, S. El. -Din and H. Etaiw, Spectrochimica Acta, Part A, 2002, 58, 3011.

19. S. .K. Ghosh and S. C. Bhattacharya, Chem. Phys. Lipids. 2004, 131, 151.

20. S. K. Ghosh and P. K. Khatua, J. Colloid Interface Sci. 2004, 279.

21. L.N. Pattnaik, P. L. Nayak, and M.K. Rout, J. Indian Chem. Soc., 1967, 44, 668.

22. D.N. Panda, P.L. Nayak and M.K. Rout, Indian J. Chem., 1969, 7, 469.

23. A. Fischer, J. Packer, and J. Vaughan, J. Chem. Soc. 1962, 3318.

24. A. K. Panigrahi, S. Misra, M. Patra and B. K. Sinha, Indian J. Chem. Sect. A, 1996, 35, 861.

25. B. Jena, A. K. Panigrahi, and B. K. Sinha, Asian J. Chem., 1994, 6, 566.

26. J. G. Lee. I. S. Park, and J. W. Seo, Bull. Korean Chem. Soc., 1995, 16, 349.

27. J. P. Guthrie, J. Cossor, and J.Q. Liu. Can. J. Chem., 1991, 69, 1904.

28. Lalan Kumar, S. N. Prasad and S.P. Singh, J. Chemtracs, 2000, 2, 79.

29. Anita Singh, S.P. Singh,D. C. Mandal,V. Kumar and B. Singh Vijnana Parishad Anusandhan Patrika, 2004, 47, 367.

30. F. R. Faizi, M. A.Khan, Vijay Kumar P.K. Chauraisa and S. P. Singh, J. Chemtracks, 2004, 6, 59.

31. F. R. Faizi, K. Ahmad, O. P. Srivastava, Vinita and S.P. Singh J. Chemtracks, 2005, 7, 117.

32. Geeta Kumari, R. K. Bharti, K. Ahmad, S. K. Srivastava, A. k. Ojha and S. P. Singh $J$. Chemtracks, 2009, 11(2), 401.

33. Khursheed Ahmad S. K. Srivastava, B. Kumar, R. Kumar O. P. Srivstava and S.P. Singh J. Chemtracks, 2010, 12(1), 147.

34. Jai Prakash Kumar and S. P. Singh J. Chemtracks, 2016, 18(1), 57.

35. Pragati Kiran, S. R. K. Singh and S. P. Singh J. Chemtracks, 2016, 18(2), 353.

36. S. K. Sahay and M.K. Roy J. Chemtracks, 2017, 19(1), 103.

37. S. K. Sahay and K.K. Seth J. Chemtracks, 2017, 19(2), 201.

38. J. R. Mirror and M. Boulet J. Dairy Science, 1983, 41, 1683. 